\title{
Telephone Consultation in Otorhinolaryngology During the Coronavirus Disease 2019 Pandemic: a Cross-sectional Analysis of Effectiveness and Satisfaction for Patients and Clinicians
}

\author{
Ramanathan Swaminathan ${ }^{1}$ (D) Zahir Mughal ${ }^{1} \cdot$ David Phillips $^{1}$
}

Accepted: 6 January 2022 / Published online: 12 January 2022

(c) Crown 2022

\begin{abstract}
The COVID-19 pandemic has necessitated measures to minimise face-to-face interaction. We assessed the efficacy of teleconsultation and patient satisfaction in adult otorhinolaryngology clinic. A prospective review of telephone consultations over 6 months in a single district general hospital was conducted. Data was collected on the characteristics and outcomes of teleconsultations by clinicians, and a questionnaire was sent to patients. Of 304 telephone consultations, 115 were new and 189 were follow-up. Five percent of patients were listed for surgery. The discharge rate was $31 \%$, largely comprising of patients with otorhinolaryngological symptoms. High clinician and patient satisfaction were reported by $90 \%$ and $96 \%$, respectively. Telephone consultation was a good one-stop treat and discharge service for a number of otorhinolaryngological complaints such as hearing loss, tinnitus and recurrent tonsillitis. Patient and clinician satisfaction was high. Careful triaging of referrals for telephone consultation can potentially reduce the number of face-to-face clinic appointments.
\end{abstract}

Keywords COVID-19 $\cdot$ Outpatients $\cdot$ Referral and consultation $\cdot$ Telemedicine

\section{Introduction}

The coronavirus disease 2019 (COVID-19) pandemic has overwhelmed healthcare services worldwide and has necessitated the adoption of novel ways of practice [1]. The high transmissibility of the severe acute respiratory syndrome coronavirus 2 (SARS-CoV-2) virus compounded by environmental factors such as enclosed spaces and crowding has led to the need for travel restrictions and social distancing [2]. This coupled with the need for redeployment and restructuring of services has resulted in postponement of elective procedures and a reduction in outpatient services [3].

The need to continue the provision of vital outpatient services and avoid unnecessary face-to-face hospital appointments has led to an increase in the use of telephone consultation $[1,3]$. Telephone consultation has been practised in primary care for a considerable time, well before the

This article is part of the Topical Collection on Covid-19

Ramanathan Swaminathan

Ramanathan.Swaminathan@swft.nhs.uk

1 Department of Otorhinolaryngology, Warwick Hospital, Lakin Road, Warwick CV34 5BW, UK
COVID-19 pandemic [4]. Telephone consultation has not been an established method of consultation in otorhinolaryngology despite its potential in managing a wide array of otorhinolaryngology conditions [5]. We evaluated the application of outpatient telephone consultations during the COVID-19 pandemic in otorhinolaryngology to determine whether it is an effective, sustainable and acceptable outpatient model that could be continued in the post-pandemic era.

\section{Methods}

A prospective cross-sectional study was conducted amongst the otorhinolaryngologists at a district general hospital in the West Midlands, UK. An in-house hard copy questionnaire for clinicians was designed to ascertain the clinical tasks undertaken during telephone consultation. The clinician questionnaire consisted of 30 items as shown in Fig. 1. This was completed prospectively by clinicians during telephone consultations over a 6-month period from October 2020 to March 2021. All referrals were triaged for telephone consultation by clinical nurse specialists in otorhinolaryngology. Triaging was based on the general practitioners' referral 
Fig. 1 Clinician data collection form. Evolve, electronic patient records programme; ICE, electronic haematology and pathology reporting programme;

PACS, picture archiving and communication system for radiology; F2F, face-to-face; FNE, fibreoptic nasendoscopy; DNA, did-not-attend; VCA, voice call appointment

\begin{tabular}{|c|c|c|c|}
\hline General & & $\begin{array}{l}\text { Format of } \\
\text { answer }\end{array}$ & Answers \\
\hline 1 & Clinicians Name & state & \\
\hline 2 & Date of clinic & $\mathrm{dd} / \mathrm{mm} / \mathrm{yy}$ & \\
\hline 3 & Patient Record number & Numbers & \\
\hline 4 & Date of Birth & $\mathrm{dd} / \mathrm{mm} / \mathrm{yy}$ & \\
\hline 5 & New or follow up & $\mathrm{N}$ or $\mathrm{FU}$ & \\
\hline 6 & $\begin{array}{l}\text { Follow up: } \\
\text { Yours/Yours/another clinician }\end{array}$ & Mine/other & \\
\hline \multicolumn{4}{|l|}{ Clinical } \\
\hline 7 & Main symptoms & 1. state & \\
\hline 8 & & 2. state & \\
\hline 9 & & 3. state & \\
\hline \multicolumn{4}{|l|}{$\begin{array}{l}\text { Investigations } \\
\text { arranged }\end{array}$} \\
\hline 10 & Imaging & State form & \\
\hline 11 & Bloods & State types & \\
\hline 12 & Audiology & State form & \\
\hline 13 & Drugs Prescribed & State names & \\
\hline 14 & Refer Hearing Aid & Yes or No & \\
\hline 15 & Refer Tinnitus counselling & Yes or No & \\
\hline \multicolumn{4}{|l|}{ Diagnosis } \\
\hline 16 & Provisional & 1. state & \\
\hline 17 & Firm & 2. state & \\
\hline Disposal & & Tick one & \\
\hline 18 & 1a. Discharged & & \\
\hline 19 & $\begin{array}{l}\text { 1b. Discharged with contact } \\
\text { details - if so state }\end{array}$ & & \\
\hline 20 & $\begin{array}{l}\text { 1c. Discharged letter with } \\
\text { results to follow - state }\end{array}$ & & \\
\hline 21 & 2. Follow up & & \\
\hline 22 & 3. F2F Specify reason & & \\
\hline 23 & 3a. F2F FNE & & \\
\hline 24 & 3b. F2F Ear & & \\
\hline 25 & 4a. DNA - discharged & & \\
\hline 26 & 4b. DNA - option to return & & \\
\hline 27 & 5. Listed & State operation & \\
\hline 28 & 6. Refer another discipline & state & \\
\hline $\begin{array}{l}29 \text { Clinician's } \\
\text { comfort in VCA }\end{array}$ & $\begin{array}{l}\text { 1. Uncomfortable } \\
\text { 2. Content at diagnosis } \\
\text { 3. Pleasing }\end{array}$ & $\begin{array}{l}\text { Choose one } \\
\text { number }\end{array}$ & \\
\hline 30 Comments & & & \\
\hline
\end{tabular}

letters and the information provided. Where appropriate, pure tone audiograms and tympanograms were arranged prior to the consultation. Unfortunately, we did not collect data on the number of requests made for audiometry before the telephone consultation. Inclusion criteria included both new and follow-up patients. The wide range of patients with different otorhinolaryngological complaints was triaged for telephone consultation as shown in Table 1. Exclusion criteria included patients that warranted face-to-face consultation such as 2-week-wait head and neck referrals and referrals for acute symptoms such as discharging ears and unilateral nasal symptoms.
All patients who participated in a telephone consultation were invited to provide feedback via a postal survey with pre-paid return postage over 2-month period from December 2020 to February 2021. A modified questionnaire from Centre of Care Innovation, California [6], was used and is provided in Fig. 2. This was a 12-item questionnaire with a four-point Likert rating scale from strongly agree to strongly disagree [7].

This study did not require ethics approval according to the UK NHS Health Research Authority decision tool [8]. Data analysis was conducted in Microsoft Excel (Redmond, WA, USA). Statistical analyses were performed in GraphPad 
Table 1 Symptoms and diagnoses of new and follow-up patients that underwent teleconsultation

\begin{tabular}{|c|c|c|c|c|c|}
\hline \multicolumn{3}{|l|}{  } & Type & Symptom & \multirow[t]{2}{*}{ Percentage } \\
\hline Type & Symptom & Percentage & Follow-up & & \\
\hline \multicolumn{3}{|l|}{ New patients } & Otology & Hearing loss & 15.6 \\
\hline \multirow[t]{15}{*}{ Otology } & Tinnitus & 18.9 & & Tinnitus & 5.3 \\
\hline & Hearing loss & 17.9 & & Vertigo & 5.3 \\
\hline & Vertigo & 5.6 & & Ear pain & 4.3 \\
\hline & Ear discharge & 4.6 & & Ear discharge & 4.0 \\
\hline & Ear pain & 2.6 & & Ear pain & 3.0 \\
\hline & Dizziness & 2.0 & & Ear infection & 1.7 \\
\hline & Balance problems/unsteadiness & 1.0 & & Grommet & 1.3 \\
\hline & Pulsatile tinnitus & 1.0 & & OME & 1.0 \\
\hline & Blocked ear & 1.0 & & Mastoid cavity & 0.7 \\
\hline & Ear infection & 1.0 & & Blocked ear & 0.7 \\
\hline & Ear wax & 1.0 & & Perforated tympanic membrane & 0.7 \\
\hline & Folded ear & 0.5 & & Pulsatile tinnitus & 0.7 \\
\hline & Nose pain & 0.5 & & Itchy ears & 0.7 \\
\hline & Ear crackling & 0.5 & & Awaiting myringoplasty & 0.3 \\
\hline & Pressure in ear & 0.5 & & Ear symptoms & 0.3 \\
\hline \multirow[t]{10}{*}{ Rhinology } & Nasal obstruction & 8.2 & & Post mastoid & 0.3 \\
\hline & Headache & 4.6 & & Smell from ear & 0.3 \\
\hline & Nosebleed & 3.6 & & Ear fullness & 0.3 \\
\hline & Anosmia/hyposmia/cacosmia & 3.1 & & Meniere's disease & 0.3 \\
\hline & Facial pain & 2.6 & & Sensation of fluid & 0.3 \\
\hline & Catarrh & 1.0 & & Hyperacusis & 0.3 \\
\hline & Rhinorrhoea & 1.0 & & Speech delay & 0.3 \\
\hline & Postnasal drip & 1.0 & & BPPV & 0.3 \\
\hline & Loss of taste & 0.5 & & Cholesteatoma & 0.3 \\
\hline & Nasal burning & 0.5 & & $\mathrm{AOE}$ & 0.3 \\
\hline \multirow[t]{16}{*}{ Head and neck } & Sore throat & 3.1 & & Hearing aid not working & 0.3 \\
\hline & Cough & 1.5 & Rhinology & Nasal obstruction & 8.6 \\
\hline & Tonsillitis & 1.5 & & Postnasal drip & 3.0 \\
\hline & Snoring & 1.5 & & Sinusitis & 2.7 \\
\hline & Hoarse voice & 1.0 & & Loss of smell & 2.7 \\
\hline & Dysphagia & 1.0 & & Facial pain & 2.3 \\
\hline & Lump ear & 0.5 & & Headache & 2.0 \\
\hline & Lump jaw & 0.5 & & Nasal discharge & 2.0 \\
\hline & Lump throat & 0.5 & & Nosebleed & 1.3 \\
\hline & Throat closing & 0.5 & & Nasal polyp & 0.7 \\
\hline & Oral blood & 0.5 & & Sore nose & 0.3 \\
\hline & Tonsil stones & 0.5 & & Hay fever & 0.3 \\
\hline & Respiratory pauses & 0.5 & & Deviated septum & 0.3 \\
\hline & Neck pain & 0.5 & & Fullness of head & 0.3 \\
\hline & Reflux & 0.5 & & Nasal crusting & 0.3 \\
\hline & Throat clearing & 0.5 & & Bad smell nose & 0.3 \\
\hline Other & Post trauma & 0.5 & & Rhinitis & 0.3 \\
\hline \multirow[t]{5}{*}{ Diagnosis (top 5) } & Sensorineural hearing loss & 15.2 & & Sneezing & 0.3 \\
\hline & Laryngopharyngeal reflux & 8.9 & & & \\
\hline & Chronic sinusitis & 6.3 & & & \\
\hline & Chronic rhinitis & 5.4 & & & \\
\hline & Otitis externa, Meniere's disease & 4.5 & & & \\
\hline
\end{tabular}

Table 1 (continued) 
Table 1 (continued)

\begin{tabular}{|c|c|c|}
\hline Type & Symptom & Percentage \\
\hline \multirow[t]{21}{*}{ Head and neck } & Lump neck & 2.7 \\
\hline & Snoring & 1.7 \\
\hline & Sore throat & 1.7 \\
\hline & Hoarse voice & 1.3 \\
\hline & Tonsillitis & 1.0 \\
\hline & Sleep apnoea & 1.0 \\
\hline & Lump parotid & 0.7 \\
\hline & Reflux & 0.7 \\
\hline & Choking & 0.7 \\
\hline & Blisters & 0.3 \\
\hline & Burning in mouth & 0.3 \\
\hline & Neck pain & 0.3 \\
\hline & Oral thrush & 0.3 \\
\hline & Mouth ulcers & 0.3 \\
\hline & Lump thyroid & 0.3 \\
\hline & Globus & 0.3 \\
\hline & Facial palsy & 0.3 \\
\hline & Foreign body sensation & 0.3 \\
\hline & Halitosis & 0.3 \\
\hline & Cough & 0.3 \\
\hline & Dysphagia & 0.3 \\
\hline \multirow[t]{3}{*}{ Other } & Post-operative review & 7.0 \\
\hline & Foreign body & 0.3 \\
\hline & Recurrent falls & 0.3 \\
\hline \multirow[t]{5}{*}{ Diagnosis (top 5) } & Chronic sinusitis & 8.8 \\
\hline & Sensorineural hearing loss & 8.2 \\
\hline & Post OP & 7.1 \\
\hline & Chronic rhinitis & 6.5 \\
\hline & $\begin{array}{l}\text { Ear wax, cholesteatoma, deviated } \\
\text { nasal septum, otitis externa }\end{array}$ & 3.5 \\
\hline
\end{tabular}

Prism 5 (San Diego, CA, USA). Summary statistics were presented according to the normality of the data, mean and standard deviation (SD). The unpaired two-tailed Student's $t$-test was used to compare the age of patients in the new and follow-up groups.

\section{Results}

\section{Clinicians' Perspective}

Clinician questionnaires were prospectively completed for 304 consultations over the study period. The consultations were conducted by ten clinicians, comprising consultants (30\%), associate specialists (49\%) and registrars (21\%). The mean age of the patients was 45 years (SD 25). Out of the 304 consultations, 115 (38\%) were new and $189(62 \%)$ were follow-up appointments. There was no significant difference in age of patients between new and follow-up cohorts $(p=0.502)$.

The commonest symptoms in newly referred patients were tinnitus (19\%), hearing loss $(18 \%)$, nasal obstruction $(8 \%)$, vertigo $(6 \%)$, headache $(5 \%)$ and otorrhoea $(5 \%)$. The most common diagnoses made from telephone clinic were sensorineural hearing loss mainly presbyacusis (15\%), laryngopharyngeal reflux (9\%), chronic sinusitis $(6 \%)$, chronic rhinitis $(5 \%)$, otitis externa $(5 \%)$ and Meniere's disease $(5 \%)$. The diagnosis of otitis externa was made from past history and from other clinicians' examinations. The common symptoms in follow-up patients were hearing loss (16\%), nasal obstruction (9\%), post-operative reviews (7\%, comprising of septoplasty, grommets and adenotonsillectomy for sleep apnoea), tinnitus (5\%), vertigo (5\%), ear pain (4\%) and ear discharge $(4 \%)$. The common follow-up patient diagnoses were chronic rhinosinusitis (9\%), sensorineural hearing loss (8\%), post-operative (7\%) chronic rhinitis $(7 \%)$, ear wax, cholesteatoma and deviated nasal septum (7\%). The complete list of symptoms and diagnoses are listed in Table 1, including those seen in new and follow-up patients.

Of the 304 telephone consultations, 93 (31\%) were discharged of which 59 (63\%) were follow-up patients and $34(36 \%)$ were new patients, with incomplete data for one patient. The discharge rate for new patients was $30 \%$. Out of the 34 new patients that were discharged, $62 \%$ of patients belong to the otology group with symptoms of hearing loss, tinnitus and vertigo. The patient discharge rate in the followup group was $31 \%$. Most of the patients discharged in this cohort belonged to the otology $42 \%$ (hearing loss, vertigo) and post-operative group 19\% (septoplasty, grommet, turbinate surgery, nasal polyp). The telephone consultations generated several outpatient clinical activities for new and follow-up patients, such as referral to audiology, imaging, blood tests and tinnitus counselling which are listed in Table 2. The cases that were added to the waiting list for surgery following a telephone consultation were $n=14(5 \%)$ and included tonsillectomy, septoplasty, turbinate surgery, parotidectomy and mastoid surgery, as outlined in Table 2. Three patients, all new, provided a good history of recurrent acute tonsillitis and were listed for surgery without being seen. They were given a detailed account of the surgery and sent patient information leaflets. The remainder had been previously seen and the purpose of the telephone consultation was to feedback the results of investigations and consent for surgery.

The did-not-attend (DNA) rate for teleconsultation during the study period was $7.5 \%$. We compared this to the 
Fig. 2 Patient satisfaction questionnaire
Table 2 Clinical activities generated by telephone consultations

\begin{tabular}{|l|l|l|l|l|}
\hline $\begin{array}{l}\text { Have you ever had a telephone } \\
\text { consultation before? (Please circle) }\end{array}$ & \multicolumn{2}{|c|}{ Yes } & \multicolumn{2}{|c|}{ No } \\
\hline \multicolumn{2}{|c|}{ Tell us how much you agree or disagree with the following statements on a scale of - 4. } \\
\hline & $\begin{array}{l}\text { Strongly } \\
\text { Disagree }\end{array}$ & Disagree & Agree & $\begin{array}{l}\text { Strongly } \\
\text { Agree }\end{array}$ \\
\hline $\begin{array}{l}\text { My telephone consultation was easy } \\
\text { to schedule }\end{array}$ & 1 & 2 & 3 & 4 \\
\hline My consultation started on time & & & & \\
\hline $\begin{array}{l}\text { The doctor explained things in a way } \\
\text { that was easy to understand }\end{array}$ & & & & \\
\hline The doctor listened carefully to me & & & & \\
\hline $\begin{array}{l}\text { The doctor spent enough time with } \\
\text { me }\end{array}$ & & & & \\
\hline $\begin{array}{l}\text { I could hear the doctor clearly when } \\
\text { he/she spoke to me }\end{array}$ & & & & \\
\hline $\begin{array}{l}\text { The telephone consultation was as } \\
\text { good as an in person visit }\end{array}$ & & & & \\
\hline $\begin{array}{l}\text { I would have received better quality } \\
\text { care if I had seen the doctor in person }\end{array}$ & & & & \\
\hline $\begin{array}{l}\text { The telephone consultation made it } \\
\text { easier for me to consult a doctor today } \\
\text { rather than waiting for a face-to-face } \\
\text { appointment }\end{array}$ & & & & \\
\hline $\begin{array}{l}\text { Overall, I was satisfied with the } \\
\text { consultation }\end{array}$ & & & & \\
\hline $\begin{array}{l}\text { I would use a telephone consultation } \\
\text { again }\end{array}$ & & & & \\
\hline Your occupation & & & \\
\hline $\begin{array}{l}\text { If we could improve one thing about } \\
\text { your telephone consultation, what } \\
\text { would it be? }\end{array}$ & & & & \\
\hline
\end{tabular}

\begin{tabular}{llll}
\hline & \multicolumn{2}{l}{ Number (percentage) } & \\
\cline { 2 - 4 } & Total appointments & New patients & Follow-up patients \\
\hline Imaging & $60(20 \%)$ & $30(26 \%)$ & $30(16 \%)$ \\
Bloods & $16(5)$ & $10(9 \%)$ & $6(3 \%)$ \\
Audio & $36(12 \%)$ & $18(16 \%)$ & $18(10 \%)$ \\
Drugs prescribed & $17(6 \%)$ & $9(8 \%)$ & $8(4 \%)$ \\
Hearing aid referral & $22(7 \%)$ & $11(10 \%)$ & $11(6 \%)$ \\
Tinnitus counselling & $15(5)$ & $12(10 \%)$ & $3(2 \%)$ \\
Listed for surgery & $14(5 \%)$ & $3(3 \%)$ & $11(6 \%)$ \\
& & Tonsillectomy $(n=3)$ & Tonsillectomy $(n=3)$ \\
& & & Adenoidectomy \\
& & & $(n=1)$ \\
& & & Septoplasty $(n=2)$ \\
& & & Septoplasty and \\
& & turbinate reduction \\
& & & $(n=1)$ \\
& & & Turbinoplasty $(n=1)$ \\
Onward referral to other & $9(3 \%)$ & Parotidectomy $(n=2)$ \\
discipline & & & Mastoidectomy \\
& & & $(n=1)$ \\
& & & $6(3 \%)$ \\
& & & \\
\hline
\end{tabular}


pre-pandemic DNA rate for face-to-face appointments during October and March months and found the rate was similar at $7.6 \%$. Overall, clinicians reported their comfort level with teleconsultation as pleasing in $29 \%$, comfortable in $61 \%$ and uncomfortable in $8 \%$. Clinicians expressed feeling uncomfortable while conducting telephone consultations on patients with the diagnoses of otitis media with effusion, tympanic membrane perforation, referred otalgia, nasal polyp and chronic sinusitis.

No adverse patient event such as formal complaints was reported during the study period in any of the patients included in the study.

\section{Patients' Perspective}

A total of 378 patient questionnaires were disseminated, and 144 responded providing a response rate of $38 \%$. Of the patients consulted, $65 \%$ had previous experience of telephone consultation. A summary of the questionnaire responses can be found in Fig. 3.

Ease of scheduling telephone consultations was evaluated, with $93 \%$ agreeing and $7 \%$ disagreeing. Of the respondents, $87 \%$ agreed and $13 \%$ disagreed that clinic appointments took place at the allocated time. The length of clinic consultation was deemed adequate by $99 \%$ of patients.

Ease of understanding of explanations offered by clinicians was assessed with $97 \%$ satisfied by their clinician. Patient perspectives of clinicians' listening skills via telephone clinic were evaluated with $98 \%$ agreeing and $2 \%$ disagreeing. Some $92 \%$ agreed that they could hear the clinicians speak clearly; however, $8 \%$ felt that speech was not clearly audible.

When asked if the telephone consultations were as good as in person, $54 \%$ agreed and $46 \%$ disagreed. A proportion of patients (49\%) felt that they would have received better quality of care had they seen a doctor in person.
The majority of the respondents (85\%) felt that the waiting time to consult a doctor was reduced with access to telephone clinic quicker than face-to-face clinics. Overall, $96 \%$ were satisfied with the consultation and $89 \%$ stated that they would participate in a telephone clinic again. Suggestions for improvement included using video conferencing and offering a choice of in-person consultations.

\section{Discussion}

There is evidence that otorhinolaryngologists in the UK are amongst the highest risk of specialities to acquire the COVID-19 infection [9]. The current otorhinolaryngologyspecific guidance in the UK advocates the restructuring of outpatient pathway structures to protect patients and clinicians alike in the pandemic [10]. Recovery and returning to pre-pandemic activity levels in hospitals is likely to take several years and alternative ways of working will serve to maintain service provision while ensuring patient safety. Clinicians have been quick to adapt to change, and telephone consultation is becoming an increasingly accepted practice after the COVID-19 pandemic [11]. In the pre-COVID-19 era, most studies on telephone consultation were conducted in primary and secondary care, including medical specialities with few in the surgical settings $[12,13]$. Despite some innovations and technological advancements in this area, telephone consultation in the UK is not an entrenched way of practice [14].

Our study showed that the overall patient satisfaction on telephone consultation was high and the majority would use this mode of consultation again. This high level of patient satisfaction level is comparable to other studies $[14,15]$. The high patient satisfaction on telephone consultation may be related to various factors such as ease of consultation from home without the need to travel, reduced risk of contracting the infection and the associated
Fig. 3 Summary of the questionnaire responses

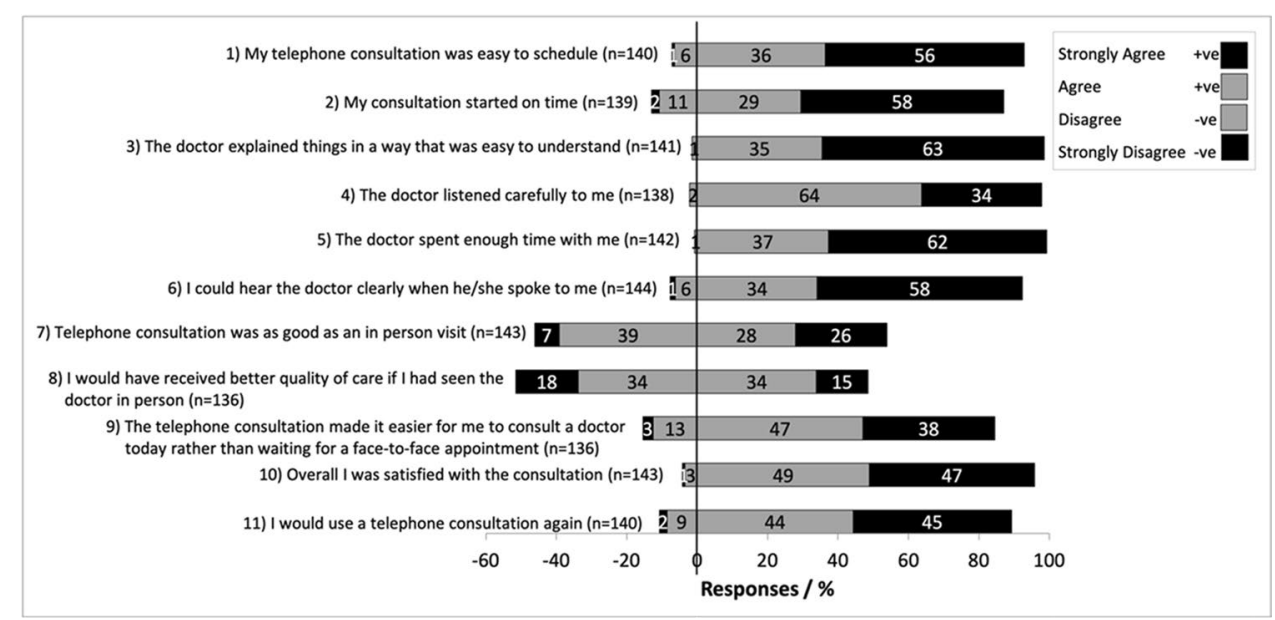


financial benefits for the patient and organisation. If the current adaptations are strengthened and improved, the same satisfaction level will continue beyond the COVID19 pandemic. This will require the use of NHS-approved video platforms and providing standardised consultation formats.

A key step in delivering this service will be careful triaging of patients suitable for telephone consultation. Traditionally otorhinolaryngologists have relied on direct examination to aid diagnosis; however, with technological advancements, it is now possible to make a reliable diagnosis via good quality photographs and video recordings. Our study showed that a range of diagnoses were established via telephone clinics including conditions such as sensorineural hearing loss, presbyacusis, chronic sinusitis and rhinitis, laryngopharyngeal reflux and recurrent tonsillitis. About a third of our patient cohort were discharged from clinic following effective counselling and initiation of treatment in some instances based purely on these consultations. Indeed, a group of patients who had telephone consultation were also listed for surgery, which included tonsillectomy. It was encouraging that no patient safety issues were identified such as inappropriate listing or inadequate counselling prior to surgery.

Patients who were discharged mainly belonged to the group with otological conditions such as hearing loss, tinnitus and vertigo. Some of these patients were referred to hearing services for aiding or tinnitus counselling. We found that remote consultations were particularly effective in the post-operative group where progress and response to surgery could be monitored; in the pre-operative group for counselling about the surgery and in patients who required explanation of results of investigations.

The clinicians conducting the telephone consultations have expressed positive views on overall comfort levels. Given that most clinicians have been quick to adapt to changes, these comfort levels may be sustained by providing appropriate training sessions to optimise communication skills and reinforce behaviours around protecting patient confidentiality. Providing a supportive and constructive environment to discuss difficulties encountered with telephone consultation and sharing clinician experience in peer review groups should be incorporated into the governance structure of units undertaking telephone clinics.

We demonstrated that telephone clinics were conducted by clinicians of all grades with differing levels of expertise. A significant contribution to reducing the outpatient waiting list was made by one clinician shielding during the pandemic, thus highlighting the productivity that may be achieved by the cohort of clinicians required to shield for healthcare reasons.

Our findings demonstrated that telephone consultation was suitable for both new referrals and follow-up patients.
The strengths of our study included prospective data collection of a sizeable number of patients. Our survey was conducted via a postal paper form and was anonymous. This had the advantage of minimising acquiescence bias, which is the tendency to agree in surveys. This can be a problem when feedback is sought directly by clinicians via telephone as was the methodology in other studies of telephone consultation [16]. As our study demonstrates, telephone consultation in adults has various advantages. Other studies have also demonstrated a reduction in nonattendance rates, cost-effectiveness and continuity of patient care $[16,17]$.

There were a number of study limitations, including the voluntary patient survey. There was evidence that selection bias had affected our sample of patients as the respondents were skewed to having previous experience in telephone consultation (65\%). We did not use an identifier to link the clinician to the patient satisfaction questionnaires, which may have helped overcome selection bias. A proportion of patients felt that they would have received better quality of care had they seen a doctor in person; however, we did not obtain further information in this respect which would have helped explore how their experience with telephone consultation could be enhanced. The number of clinician questionnaires completed does not truly represent the total telephone consultation carried out during the study period. No adverse patient events were reported to date, but it is accepted that the time lapse since completion of the study has been short. This study had been carried out in a single centre in the UK and while some of the findings may be generalisable, multi-centre studies would be beneficial.

Further research and multicentre studies are called for to sustain the progress made in the use of telephone consultation in otorhinolaryngology. This may allow the development of local protocols that can automate the triaging of suitable conditions for telephone consultation. With adequate training of the advances in technology, clinicians can be relied upon to diagnose a range of conditions remotely. To quote a few advances, the use of video otoscopy in patients with ear symptoms and post grommet insertion can be consulted via video platforms. Personal smartphones are increasingly equipped with high-resolution photograph capabilities and have been used for assessing acute nasal fractures with good results [18]. Digital imaging of lesions in the mouth and oropharynx can be magnified, which may potentially assist in diagnosis. Children with sleep apnoea can also be seen on video consultation to allow assessment of the tonsils or any video recording on smartphones by parents can be shared. Further research is needed to explore the utilisation of telephone consultation and telemedicine in specific otorhinolaryngology presentations. 


\section{Conclusion}

Telephone consultation in otorhinolaryngology has been beneficial during the COVID-19 pandemic. Our results show positive perceptions from both clinicians and patients. Many telephone consultations led to acceptable delivery of clinical care. Robust IT is essential for the future of telephone consultation. We conclude that with organisational planning and effective training, telephone consultation in otorhinolaryngology will benefit both patients and the health service even in the post-COVID-19 landscape.

Acknowledgements Thank you to the clinical nurse specialists for their triaging task; secretarial staff for sending out patient questionnaires and clinicians and patients for their contribution to our data

Author Contribution All authors have contributed to this article. I, $\mathrm{Mr}$ R. Swaminathan, conceptualised, designed the study, collected and analysed data and finalised the report. Mr. Z. Mughal contributed to data collection and analysis and reviewed the final report. Mr David Phillips designed the study and he is the supervising author.

Data Availability Raw data available on request.

Code Availability Not applicable.

\section{Declarations}

Ethics Approval This work was considered a service improvement project and ethics approval was not deemed necessary.

Consent to Participate Was voluntary.

Consent for Publication There is no patient identifiable data in the article. So this section is not applicable.

Conflict of Interest The authors declare no competing interests.

\section{References}

1. Smith AC, Thomas E, Snoswell CL, et al. Telehealth for global emergencies: implications for coronavirus disease 2019 (COVID19). J Telemed Telecare. 2020;26:309-13. https://doi.org/10.1177/ 1357633 X20916567.

2. Azuma K, Yanagi U, Kagi N, Kim H, Ogata M, Hayashi M. Environmental factors involved in SARS-CoV-2 transmission: effect and role of indoor environmental quality in the strategy for COVID-19 infection control. Environ Health Prev Med 2020;25:66. Published 2020. https://doi.org/10.1186/ s12199-020-00904-2

3. Sykes A, Pandit M. Experiences, challenges, and lessons learnt in medical staff redeployment during response to COVID-19. BMJ Leader 2021; leader-2020-000313. https://doi.org/10.1136/ leader-2020-000313

4. Bashshur RL, Howell JD, Krupinski EA, Harms KM, Bashshur N, Doarn CR. The empirical foundations of telemedicine interventions in primary care. Telemed J E Health. 2016;22:34275. https://doi.org/10.1089/tmj.2016.0045.

5. McCool RR, Davies L. Where does telemedicine fit into otolaryngology? An assessment of telemedicine eligibility among otolaryngology diagnoses. Otolaryngol Head Neck Surg. 2018;158:641-4. https://doi.org/10.1177/0194599818757724.

6. https://www.careinnovations.org. April 2021

7. Likert R. A technique for measurement of attitudes. Archives of Psychology. 1932;140:5-55.

8. Medical Research Council (MRC) Regulatory Support Centre and the Health Research Authority (HRA). Is my study research? http://www.hra-decisiontools.org.uk/research/.

9. Stephenson K, Sowerby LJ, Hopkins C, Kumar N. The UK national registry of ENT surgeons with coronavirus disease 2019. J Laryngol Otol. 2020;134:665-9. https://doi.org/10.1017/S0022 215120001747.

10. A graduated return to elective ENT within the COVID-19 pandemic. ENT UK at The Royal College of Surgeons of England. https://www.ent.org/A Graduated Return to Elective ENT within the COVID, new version.pdf (entuk.org)

11. Bokolo Anthony Jnr. Use of telemedicine and virtual care for remote treatment in response to COVID-19 pandemic. J Med Syst 2020;44:132. Published 2020 Jun 15. https://doi.org/10.1007/ s10916-020-01596-5

12. Fatehi F, Martin-Khan M, Gray LC, Russell AW. Design of a randomized, non-inferiority trial to evaluate the reliability of videoconferencing for remote consultation of diabetes. BMC Med Inform Decis Mak 2014;14:11. Published 2014 Feb 14. https:// doi.org/10.1186/1472-6947-14-11

13. Duursma F, Schers HJ, Vissers KC, Hasselaar J. Study protocol: optimization of complex palliative care at home via telemedicine. A cluster randomized controlled trial. BMC Palliat Care 2011;10:13. Published 2011 Aug 9. https://doi.org/10.1186/ 1472-684X-10-13

14. Williams OE, Elghenzai S, Subbe C, Wyatt JC, Williams J. The use of telemedicine to enhance secondary care: some lessons from the front line. Future Healthc J. 2017;4:109-14. https://doi.org/ 10.7861/futurehosp.4-2-109.

15. Rimmer RA, Christopher V, Falck A, et al. Telemedicine in otolaryngology outpatient setting-single center head and neck surgery experience. Laryngoscope. 2018;128:2072-5. https://doi.org/10. 1002/lary.27123.

16. Darr A, Senior A, Argyriou K, et al. The impact of the coronavirus (COVID-19) pandemic on elective paediatric otolaryngology outpatient services - an analysis of virtual outpatient clinics in a tertiary referral centre using the modified paediatric otolaryngology telemedicine satisfaction survey (POTSS). Int J Pediatr Otorhinolaryngol. 2020;138: 110383. https://doi.org/10.1016/j. ijporl.2020.110383.

17. Fieux M, Duret S, Bawazeer N, Denoix L, Zaouche S, Tringali S. Telemedicine for ENT: effect on quality of care during Covid-19 pandemic. Eur Ann Otorhinolaryngol Head Neck Dis. 2020;137:257-61. https://doi.org/10.1016/j.anorl.2020.06.014.

18. Barghouthi T, Glynn F, Speaker RB, Walsh M. The use of a camera-enabled mobile phone to triage patients with nasal bone injuries. Telemed J E Health. 2012;18:150-2. https://doi.org/10. 1089/tmj.2011.0112.

Publisher's Note Springer Nature remains neutral with regard to jurisdictional claims in published maps and institutional affiliations. 